\title{
LEGITIMIDADE DE ACESSO À REPRODUÇÃO ASSISTIDA POST MORTEM
}

\section{Raphael Rego Borges Ribeiro*}

Resumo: Neste artigo, investigamos quem é legitimado para proceder à reprodução assistida post mortem. Questionamos se apenas o cônjuge ou companheiro(a) supérstite pode utilizar os gametas criopreservados. Procedemos a consulta bibliográfica e normativa, usando o método dedutivo. Observamos que o elemento fundamental para o acesso à RAPM é o consentimento do(a) falecido(a). Concluímos que a legitimidade para a RAPM independe: (a) do estado civil de quem congelou material genético; (b) do estado civil de quem quer acesso póstumo ao material germinativo; (c) de ter havido vínculo de casamento ou união estável entre o(a) morto(a) e quem quer usar os gametas criopreservados.

Palavras-chave: Reprodução artificial; concepção assistida; procriação assistida; consentimento; legitimidade.

\section{THE LEGITIMACY TO PUT POSTHUMOUS ASSISTED REPRODUCTION INTO PRACTICE}

Abstract: In this paper, I investigated who can put posthumous assisted reproduction (PAR) into practice. I asked whether only a surviving spouse/partner can utilize the frozen gametes. I conducted a literature review and used the deductive method. I observed that the key element to PAR is the deceased donor's consent. I concluded that access to PAR is not related to (a) the deceased donor's marital status; (b) the marital status of the living person interested in putting PAR into practice; (c) the person interested in PAR having been married to or in a cohabiting relationship with the deceased donor.

Keywords: Artificial reproduction; assisted conception; assisted procreation; consent; legitimacy.

\section{INTRODUÇÃO}

A falta de legislação específica sobre a reprodução assistida post mortem (RAPM) tem gerado diversas controvérsias sobre a matéria, que vão desde a efetiva autorização para o uso da técnica até as consequências sucessórias dela decorrentes. Algumas respostas, fora do âmbito da legislação, vêm sendo sugeridas pela doutrina, pela jurisprudência e por entidades como o Conselho Federal de Medicina e o Conselho Nacional de Justiça. Atualmente, majoritariamente se aceita que o material genético de uma pessoa morta pode ser utilizado por seu cônjuge ou

\footnotetext{
* Bacharel, Mestre e Doutor em Direito pela Universidade Federal da Bahia. Graduate student e pesquisador no Health Law Centre da University of Ottawa. Professor de Direito Civil da Universidade Federal do Oeste da Bahia.
} 
companheiro(a) supérstite. Neste artigo, questionamos se a legitimidade para a reprodução assistida post mortem deve estar vinculada ao estado civil de quem congelou os seus gametas ou de quem quer se utilizar postumamente desse material germinativo. Acreditamos que não; compreendemos que o status familiar ou eventual vínculo (de casamento ou união estável) entre os envolvidos são elementos irrelevantes na determinação da legitimidade para acesso à RAPM; defendemos que o critério definidor é, na realidade, a autorização deixada por quem criopreservou o esperma ou os óvulos.

Nosso objetivo geral é demonstrar que o rol de legitimados para a RAPM não se restringe ao cônjuge ou companheiro(a) supérstite do(a) doador(a) falecido(a). Como objetivos específicos, em primeiro lugar observaremos a omissão legislativa sobre a matéria e as tentativas não-legislativas de suprir o vazio deixado pelo legislador. Em segundo lugar, perceberemos como o planejamento familiar no Brasil independe do estado civil dos envolvidos e de ter havido um vínculo de casamento ou união estável entre a pessoa que congelou o seu material genético e a pessoa que quer ter acesso póstumo a este material.

Encontramos em Konstantin Svitnev (2010, p.894) o relato que inspirou e justifica o nosso problema de pesquisa. Aos 19 anos de idade, o russo Andrei Zakharov teve de submeter a um tratamento de quimioterapia em Israel. Antes do procedimento, o jovem deixou espermatozoides criopreservados, porém sem instruções a respeito do uso desse material em caso de seu falecimento. Oito anos depois, Andrei morreu solteiro e sem filhos. Sua mãe, Ekaterina Zakharova, após alguma resistência das autoridades israelenses, conseguiu levar o sêmen criopreservado para a Rússia. Lá, em julho de 2004, cinco meses após a morte de Andrei, Ekaterina deu início às tentativas de reprodução assistida post mortem com o material genético do filho, também sendo necessárias uma doadora de óvulo e uma gestante por substituição. Em novembro de 2005, nasceu um menino saudável. Esse cenário seria possível no Brasil?

Em termos de método, procederemos a uma consulta bibliográfica à doutrina especializada, seguida pelo uso do raciocínio dedutivo. Usaremos como marco teórico e como metodologia a doutrina do Direito Civil-Constitucional.

\section{LEGITIMIDADE PARA A REPRODUÇÃO ASSISTIDA POST MORTEM (RAPM): OMISSÃO DO LEGISLADOR E TENTATIVAS NÃO-LEGISLATIVAS DE REGULAMENTAÇÃO}


A reprodução assistida post mortem (RAPM) é a concepção artificial na qual se utiliza material germinativo proveniente de doador já falecido. Trata-se de técnica possibilitada em razão da criopreservação de gametas, promovendo-se "o rompimento das raias entre a vida que surge e a morte de quem lhe deu origem, sem que o decurso do tempo seja limite a tal ruptura" (MAGALHÃES, 2010, p.51). Apesar de majoritariamente haver referências apenas ao uso de sêmen criopreservado, absolutamente nada impede que a técnica igualmente seja posta em prática com o uso de óvulos após a morte da doadora de quem estes foram extraídos. No presente artigo, trataremos apenas da concepção póstuma, não englobando a implantação post mortem de embriões que já existiam e estavam congelados no momento do óbito de um dos genitores.

O legislador brasileiro não se preocupou em regular exaustivamente a reprodução assistida. Na verdade, é consideravelmente raro que os dispositivos normativos prevejam, expressamente, as soluções necessárias para os dilemas éticos ou práticos surgidos das inovações trazidas pelas novas tecnologias, principalmente aquelas relacionadas ao campo biomédico e biotecnológico. A este respeito, Monica Aguiar (2005, p.86) sustenta que, na medida em que as técnicas científicas avançadas são principalmente absorvidas pela parcela da população que detém o poder econômico, a intervenção estatal nessas relações acaba se retardando ainda mais, "sob a equivocada percepção de ser suficiente a regulamentação ética a cargo do Conselho Federal de Medicina ou sob a desculpa de não dever o Estado imiscuir-se em relações privadas entre médicos e pacientes".

No tocante especificamente à concepção assistida post mortem, o único dispositivo de lei em sentido estrito que há sobre a matéria está no Código Civil de 2002, em seu artigo 1.597, III $^{1}$. A referida norma apenas se limita a assegurar o reconhecimento da relação de filiação e paternidade da criança concebida postumamente em relação ao marido falecido da mulher que se utilizar da técnica. É visível a insuficiência do dispositivo para sanar até mesmo as dúvidas mais básicas sobre a RAPM, inclusive: (a) se o legislador de fato autorizou a realização do procedimento; (b) se a autorização do procedimento se restringe ao uso de sêmen, mas não ao de óvulos, na medida em que a lei se refere exclusivamente ao marido morto; (c) se a RAPM é

1 Art. 1.597 - Presumem-se concebidos na constância do casamento os filhos: III - havidos por fecundação artificial homóloga, mesmo que falecido o marido. 
restrita ao material genético criopreservado de pessoas que estavam casadas no momento em que faleceram; (d) se a pessoa que quer se utilizar da RAPM deve permanecer na condição de viúvo(a); (e) se da RAPM decorrem efeitos sucessórios; (f) se outras pessoas, além do cônjuge ou companheiro(a) supérstite, podem se utilizar do material genético criopreservado.

Devemos destacar que o artigo 1597, III do Código Civil, além de ser um dispositivo muito ruim ${ }^{2}$, é inservível como norma definidora de legitimidade para acesso à RAPM. O legislador não está dizendo em momento algum que somente está autorizado o uso póstumo de gametas em uma situação específica, qual seja, quando o doador era casado, consentiu com o procedimento e a sua viúva realizou a reprodução homóloga. O que o legislador faz é dizer que, nessa circunstância específica, a prole assim gerada entende-se, por uma ficção jurídica, concebida na constância do casamento para fins de estabelecimento de filiação presumida. Na realidade, o que o legislador deveria ter feito era expressamente reconhecer o vínculo de parentalidade entre a prole concebida postumamente e o(a) doador(a) já falecido, estabelecendo que não se obsta o vínculo de filiação mesmo tendo o genitor morrido antes da concepção. A referência ao casamento é completamente desnecessária e anacrônica, na medida que em pleno século XXI não faz qualquer sentido (tecnológico ou social) permanecer estabelecendo vínculo de filiação com base na relação (formal) entre os genitores. Isso é particularmente problemático em termos das hipóteses de reprodução assistida, notadamente nas quais, em vez da biologia ou de relações de casamento/união estável, é no consentimento das partes que se submetem ao procedimento que consiste o critério definidor da parentalidade em relação à prole. Por outro lado, o legislador deixou de fora da presunção de parentalidade as hipóteses de união estável e, mesmo em se tratando de casamento, da parentalidade decorrente do uso póstumo de óvulos criopreservados. Essa omissão normativa não autoriza que entendamos que a RAPM é vedada nas referidas hipóteses - nem poderia ser, sob pena de restar configurada uma inconstitucionalidade por violação à isonomia entre diferentes entidades familiares. Assim, reiteramos que o artigo 1597, III não é uma norma limitadora do acesso à RAPM. Por conta do silêncio legislativo sobre a questão, os questionamentos sobre a concepção póstuma exigiram tomadas de posição por parte da doutrina, da jurisprudência e de entidades como o Conselho Federal de Medicina e o Conselho Nacional de Justiça.

2 De fato, em nossa opinião, depois que o Supremo Tribunal Federal declarou a inconstitucionalidade do artigo 1790, o artigo 1597 atualmente ocupa a constrangedora posição de pior norma de todo o Código Civil de 2002. 
Sobre a reprodução assistida post mortem, buscando interpretar o mencionado artigo 1597, III do Código Civil de 2002, os doutrinadores reunidos na I Jornada de Direito Civil aprovaram o Enunciado 106, que estabelece que

Para que seja presumida a paternidade do marido falecido, será obrigatório que a mulher, ao se submeter a uma das técnicas de reprodução assistida com o material genético do falecido, esteja na condição de viúva, sendo obrigatória, ainda, a autorização escrita do marido para que se utilize seu material genético após sua morte.

É muito importante percebermos que o referido Enunciado também não se direciona a condicionar o acesso à RAPM (a) ao estado civil da pessoa morta; (b) ao estado civil de quem quer se utilizar do material genético criopreservado; (c) ao vínculo de casamento, união estável ou parentesco entre a pessoa morta e a pessoa que quer proceder à RAPM. Assim como o dispositivo normativo ao qual diz respeito, o Enunciado não se preocupa em momento algum com a legitimidade de acesso ao procedimento de reprodução assistida póstuma. A referência específica do Enunciado 106 da Jornada de Direito Civil à condição de viuvez se restringe exclusivamente ao âmbito de incidência da presunção de parentalidade do cônjuge falecido cujo material criopreservado foi utilizado no procedimento. Nos termos do mencionado dispositivo, outros cenários para a RAPM não estão vedados de modo algum; neles, contudo, a norma do artigo 1597, III não incide. (Não discutiremos aqui eventual discordância com a restrição da incidência da presunção de parentalidade em outras hipóteses.)

Em termos de jurisprudência, temos verificado há algum tempo no Brasil autorizações judiciais para que viúvas se utilizem do material criopreservado de seus maridos mortos. Um dos casos paradigmáticos é o de Katia Lenerneier, que em 2010 recebeu permissão da $13^{\text {a }}$ Vara Cível de Curitiba para proceder à desejada RAPM. Desconhecemos decisões envolvendo o uso, por cônjuges ou companheiros supérstites, de óvulos criopreservados de doadoras falecidas. Semelhantemente, mesmo após quase uma década de reconhecimento jurisprudencial das uniões e casamentos entre pessoas do mesmo sexo, desconhecemos decisões de tribunais brasileiros autorizando um homem a utilizar o esperma congelado de seu cônjuge ou companheiro falecido, ou de uma mulher a usar os óvulos de sua esposa ou companheira morta. Por fim, também não houve divulgação notória de julgados autorizando a outras pessoas, que não cônjuges ou companheiras supérstites, o uso do material genético congelado para a concepção post mortem. 
$\mathrm{Na}$ ausência de regulamentação por lei em sentido estrito a respeito das tecnologias reprodutivas de modo geral, há quase três décadas vem cabendo ao Conselho Federal de Medicina (CFM) tratar da matéria. A Resolução 1358/1992, a primeira do CFM relativamente à reprodução assistida, nada mencionou quanto à reprodução assistida post mortem. $\mathrm{O}$ máximo que dispôs foi a necessidade de, no momento da criopreservação de gametas, os cônjuges ou companheiros expressarem por escrito sua vontade ao destino dado ao material criopreservado em caso de falecimento de um deles ou de ambos. O mencionado documento foi revogado pela Resolução 1957/2010, na qual o CFM dispôs que "não constitui ilícito ético a reprodução assistida post mortem desde que haja autorização prévia específica do(a) falecido(a) para o uso do material biológico criopreservado, de acordo com a legislação vigente." Vê-se que, então, a postura do Conselho Federal de Medicina era apenas no sentido de considerar que a técnica em questão não era uma conduta médica antiética. Apesar de não haver, então, permissão expressa para a sua realização, poderia ser aplicado o princípio do direito privado segundo o qual aquilo que não está proibido está permitido. A edição posterior da Resolução 2013/2013 do Conselho Federal de Medicina revogou a Resolução 1957, especificando que a fertilização póstuma "é possível, desde que haja autorização prévia específica do(a) falecido(a) para o uso do material biológico criopreservado, de acordo com a legislação vigente". Vê-se, então, que a postura do Conselho foi alterada: em vez de simplesmente não proibir a técnica, decidiu-se por sua autorização expressa. A Resolução CFM n 2121/2015, que revogou a 2013/2013, da mesma forma estabelece que "é permitida a reprodução assistida post mortem, desde que haja autorização prévia específica do(a) falecido(a) para o uso do material biológico criopreservado, de acordo com a legislação vigente"; tal resolução igualmente se encontra revogada.

Atualmente, está em vigor a Resolução CFM nº 2168/2017. Na seção V há dispositivo (número 03) afirmando que

No momento da criopreservação, os pacientes devem manifestar sua vontade, por escrito, quanto ao destino a ser dado aos embriões criopreservados em caso de divórcio ou dissolução de união estável, doenças graves ou falecimento de um deles ou de ambos, e quando desejam doá-los.

A respeito da norma acima, apesar de se referir expressamente somente aos embriões, podemos depreender que ela se aplica também ao esperma e aos óvulos doados, na medida em que a seção $\mathrm{V}$ como um todo se refere tanto à criopreservação de embriões quanto de gametas. Assim, no momento em que um doador ou uma doadora congela o seu material genético, deverá 
manifestar sua vontade no sentido do destino que será dado àquele material em caso de sua morte. Em resumo, essa é uma oportunidade na qual, de acordo com a norma do Conselho Federal de Medicina, a pessoa pode estabelecer se - e em que condições - autoriza o uso póstumo dos seus gametas.

A mesma Resolução CFM no 2168/2017, em sua seção VIII, trata da reprodução assistida post mortem, estabelecendo que "é permitida a reprodução assistida post mortem desde que haja autorização prévia específica do(a) falecido(a) para o uso do material biológico criopreservado, de acordo com a legislação vigente". Ressaltamos que em momento algum o Conselho Federal de Medicina estabelece normas específicas sobre quem pode se valer da RAPM. Nã havendo restrição expressa ao acesso à técnica, entendemos que ao caso se aplicam as regras genéricas da seção II da Resolução 2168: são legitimadas para se submeter aos procedimentos de reprodução assistida (inclusive a post mortem) quaisquer pessoas capazes (desde que devidamente haja consentimento e esclarecimento, número 01), inclusive aquelas em relacionamentos homoafetivos ou solteiras (número 02). Observamos que, por parte da Resolução do CFM, não há qualquer limitação ao acesso à RAPM referente: (a) ao estado civil da pessoa já falecida que deixou gametas criopreservados; (b) ao estado civil da pessoa que quer usar esses gametas; (c) a qualquer vínculo estabelecido por casamento, união estável ou parentesco entre o(a) doador(a) morto(a) e a pessoa que deseja proceder à RAPM. Concluímos que, de acordo com as normas de ética médica, a reprodução assistida post mortem não está de qualquer forma ligada a considerações de estado civil; apenas ao consentimento dado nos termos da legislação.

O Conselho Nacional de Justiça tem igualmente se debruçado sobre a matéria para suprir a omissão legislativa. Especificamente sobre o registro de filhos decorrentes da reprodução assistida post mortem, o Provimento 52/2016 da Corregedoria Nacional de Justiça exigia a autorização prévia específica do falecido ou da falecida para o uso do material biológico criopreservado, consentimento este que deveria ser dado por instrumento público. $\mathrm{O}$ Provimento 63 de 2017 continuou a exigir a autorização prévia, porém passou a aceitar que esta seja dada tanto por instrumento público quanto por instrumento particular com firma reconhecida (art.17, § $2^{\circ}$ ). Ressaltamos que o CNJ tratou da questão exclusivamente sob o ângulo dos requisitos para o registro civil, dispensando a autorização judicial nos casos de assentos de nascimento nos quais os referidos requisitos tenham sido atendidos. Nem o Provimento revogado nem o vigente: (a) tratam da legitimidade de acesso à RAPM; (b) 
condicionam o registro da prole concebida por RAPM ao estado civil da pessoa que congelou seus gametas antes de morrer; (c) condicionam o registro da prole concebida por RAPM ao estado civil da pessoa que usa o material criopreservado; (d) condicionam o registro da prole concebida por RAPM ao vínculo de casamento, união estável ou parentesco entre o(a) doador(a) falecido(a) e a pessoa que se usa dos gametas congelados; (e) impedem o reconhecimento judicial da parentalidade decorrente da RAPM mesmo naqueles casos em que o procedimento foi realizado sem consentimento do(a) morto(a) devidamente formalizado.

Observamos que, no ordenamento jurídico brasileiro, não há qualquer norma que limite o acesso à reprodução assistida post mortem aos casos em que uma pessoa casada, antes de morrer, criopreservou o seu material genético e o seu cônjuge ou companheiro(a) quer se utilizar do procedimento. É plenamente possível que se proceda à RAPM com material germinativo congelado de pessoa que morreu solteira ou viúva. É igualmente plenamente possível que a RAPM seja posta em prática por iniciativa não do cônjuge ou companheiro(a) supérstite da pessoa morta, mas por um terceiro, independentemente de parentesco. Como no caso descrito na Introdução deste artigo, a mãe de um indivíduo morto que conservou o seu esperma pode se valer da RAPM para conceber um neto. Semelhantemente, o amigo de uma doadora morta pode se utilizar dos seus óvulos criopreservados, com auxílio de gestação de substituição, para gerar um filho da falecida. Para que a reprodução assistida post mortem seja realizada, são irrelevantes tanto o estado civil dos envolvidos quanto o vínculo que havia entre quem doou os gametas, enquanto vivia, e a pessoa que deles vai se utilizar postumamente. A única exigência para a legalidade da RAPM é o devido consentimento de quem criopreserva material germinativo para que este seja utilizado após a sua morte; nada mais. Mencionamos aqui devido consentimento porque a autorização pressupõe, naturalmente, todos os esclarecimentos e informações necessárias para a tomada de decisão. De todo modo, sequer se exige forma específica para esse consentimento, desde que informado e esclarecido. A forma pública ou autenticada em cartório, exigida pelo Provimento CNJ 63/2017, apenas se refere à desnecessidade de chancela judicial para o registro de nascimento.

Notamos acima que a Resolução CFM n²168/2017 estabelece em sua seção V, número 03, que no momento da criopreservação, o indivíduo manifestará vontade a respeito do destino que poderá ser dado àquele material germinativo em caso de seu falecimento. Isso se aplica a qualquer pessoa congelando esperma ou óvulos, independentemente do seu estado civil. Semelhantemente, a pessoa é livre para determinar não apenas se os gametas poderão ser 
utilizados, mas também quem terá acesso a eles. E obviamente a determinação desse quem não se limita a um eventual cônjuge ou companheiro(a). Isso se trata de um desdobramento da ideia de planejamento familiar, direito cujo exercício é tanto constitucionalmente ${ }^{3}$ quanto legalmente ${ }^{4}$ reconhecido como livre. O sujeito pode livremente estabelecer que seu material genético poderá ser utilizado para RAPM por seus próprios genitores, por um(a) amigo(a), por um(a) herdeiro(a) testamentário(a), enfim, por qualquer pessoa interessada.

Ressaltamos que, inexistindo autorização por parte da pessoa que criopreservou seus gametas, configurará ilicitude colocar em prática a RAPM. Verificamos acima que o consentimento do doador do material genético é pressuposto para o procedimento, conforme o Conselho Federal de Medicina. Além de ilícito ético-profissional, a RAPM não autorizada também se classifica como ilícito civil, por violar o princípio biojurídico básico de respeito ao consentimento informado e esclarecido das pessoas envolvidas em procedimentos médicocientíficos. Desse modo, percebemos que, se a pessoa tiver morrido sem autorizar a reprodução assistida post mortem, o procedimento não poderá ser utilizado nem mesmo pelo cônjuge ou companheiro(a) supérstite, por mais que este(a) demonstre o seu projeto parental e a sua aptidão. Dessa forma, o estado civil do(a) interessado(a) vivo(a) não supre a ausência do consentimento do(a) doador(a) falecido(a). Por essa razão, concluímos que o status familiar da pessoa interessada é irrelevante, na medida em que o critério determinante para a licitude da RAPM é a autorização deixada pela pessoa morta. Nesse sentido, se reconhecemos que a vontade manifestada é o critério determinante para a licitude do procedimento, podemos tranquilamente admitir que também se trata do elemento-chave para determinar a legitimidade de quem pode ter acesso à reprodução assistida post mortem.

\section{PLANEJAMENTo FAMILIAR E LEGITIMIdAdE PARA A REPRODUÇÃo ASSISTIDA POST MORTEM}

Uma grande inovação da Carta de 1988 foi não repetir a previsão das Constituições anteriores, segundo as quais a família seria apenas constituída pelo casamento; o novel constituinte simplesmente afirma, no caput do artigo 226, que a família é a base da sociedade e

3 Constituição Federal de 1988, art. 226, $\S 7^{\circ}$.

4 Lei 9263/1996, art. $5^{\circ}$. 
tem especial proteção do Estado. A Constituição Federal de 1988 ampliou o âmbito de proteção das entidades familiares para além do casamento, reconhecendo expressamente a união estável e a família monoparental. Do texto constitucional de 1988 podemos depreender diversos princípios relacionados ao Direito de Família, a exemplo da dignidade da pessoa humana, da igualdade entre os cônjuges, da isonomia entre os filhos, da solidariedade familiar, da proteção à criança e ao adolescente, do amparo aos idosos e da proteção ao pluralismo das entidades familiares ${ }^{5}$. Em decorrência dos mencionados princípios, o Direito de Família tem acolhido diversas formas inovadoras de convivência familiar, dando legitimidade social a "modalidades pós-modernas de família", conforme a tese de Adriana Dabus Maluf (2010). Anderson Schreiber (2013, p.313) afirma ser imperativo o reconhecimento de "redes familiares" que não podem "ser encerradas em uma ou outra categoria", trazendo como exemplos as uniões homoafetivas, as "famílias-mosaico", a "família unipessoal", entre diversas outras. Também podemos falar nas famílias ectogenéticas, aquelas criadas com o auxílio da reprodução assistida. Nesse sentido, um dos mais significativos princípios constitucionais regentes do Direito de Família é o do livre planejamento familiar.

O artigo 226, $\$ 7^{\circ}$ da Constituição Federal de 1988 consagrou o direito ao livre planejamento familiar, fundado nos princípios da dignidade da pessoa humana e da paternidade responsável. Assim, o próprio texto constitucional incumbe o Estado de proporcionar o acesso a recursos educacionais e científicos necessários ao exercício de tal direito. A previsão constitucional expressa de direito ao planejamento familiar tem relação estreita com o reconhecimento da necessidade de proteção jurídica à sexualidade e à reprodução. A respeito deste tema, Guilherme Calmon Nogueira da Gama (2003, p.444) afirma que o planejamento familiar "se encontra necessariamente relacionado à noção de direitos reprodutivos, assim considerados os direitos básicos vinculados ao livre exercício da sexualidade e da reprodução humana com os limites que lhes são inerentes". Neste sentido, as Conferências Internacionais do Cairo, de Beijing e de Copenhague reconheceram a importância da saúde reprodutiva e

5 Filiamo-nos à corrente doutrinária que reconhece na atual ordem constitucional o princípio implícito do pluralismo das famílias. Observamos como demonstração jurisprudencial do mencionado princípio a decisão do Supremo Tribunal Federal ao julgar a Ação Direta de Inconstitucionalidade 4277 e a Arguição de Descumprimento de Preceito Fundamental 132, que, a despeito de a literalidade do texto da Constituição Federal de 1988 mencionar apenas a união estável formada pelo homem e pela mulher, foi reconhecida a constitucionalidade da aplicação das regras do referido instituto à união entre casais do mesmo sexo. 
erigiram os chamados “direitos sexuais e reprodutivos” à categoria de direitos humanos.

Notamos que há corrente doutrinária que equivocadamente rejeita a existência de um direito à reprodução. Nesse sentido, Monica Aguiar (2005, p.91) defende que ter filhos é uma faculdade, não um direito irrestrito, "haja vista que a criança não pode ser vista como instrumento de um direito alheio, sob pena de, por estar a serviço do bem-estar dos pais, transmudar-se em coisa e ter valor meramente instrumental". No mesmo sentido se posiciona Eduardo de Oliveira Leite (1995, p.66), segundo quem considerar a procriação como um direito importaria em considerar o futuro filho um simples objeto do desejo dos genitores. Ocorre que, filiados ao supramencionado entendimento de Guilherme Calmon Nogueira da Gama, entendemos que o objeto do direito à procriação não é o filho em si, ou seja, não se confunde com um suposto direito à criança. Na realidade, o conteúdo dos direitos reprodutivos é a liberdade de decisão a respeito do momento de se conceber a prole e o tamanho desta, bem como a garantia de acesso aos recursos científicos e tecnológicos necessários para exercício do planejamento familiar, nos termos do quanto prevê a já referida Conferência do Cairo.

Aderimos, ainda, ao entendimento de Guilherme Frederico Hernandes Denz (2007, p.15), para quem a Constituição Federal de 1988 prevê implicitamente o direito fundamental à reprodução, decorrente notadamente dos direitos à liberdade, ao planejamento familiar e à saúde. Para o referido pesquisador (2007, p.11), o direito à procriação se manifesta em sentido negativo (impossibilidade de o Estado interferir na liberdade de planejamento familiar do casal) e em sentido positivo (obrigação de o Estado prover todos os instrumentos ao casal para poder conceber). Reiteramos que o conteúdo normativo mencionado não engloba um alegado direito à criança, motivo pelo qual não vinga o equivocado argumento de que se corre o risco de tornar um objeto o futuro ser humano. Maria Claudia Brauner (2003) leciona que a incorporação da sexualidade e da reprodução ao rol de direitos humanos "assegura às pessoas o direito ao planejamento familiar para organização da vida reprodutiva", o que implica na garantia de acesso a todos os recursos científicos que amenizem ou curem patologias ligadas à fertilidade, “desde que considerados seguros e não causadores de riscos aos usuários e usuárias".

Regulando o artigo 226, $\S 7^{\circ}$, da Constituição, o legislador positivou o planejamento familiar na Lei no 9263, de 1996, definindo-o como "o conjunto de ações de regulação da fecundidade que garanta direitos iguais de constituição, limitação ou aumento da prole pela mulher, pelo homem ou pelo casal", estabelecendo que se trata de "direito de todo cidadão", 
sendo "parte integrante do conjunto de ações de atenção à mulher, ao homem ou ao casal, dentro de uma visão de atendimento global e integral à saúde”. Por fim, a Lei 9263/96 ainda determina que "o planejamento familiar orienta-se por ações preventivas e educativas e pela garantia de acesso igualitário a informações, meios, métodos e técnicas disponíveis para a regulação da fecundidade". A respeito da referida Lei, Guilherme Calmon Nogueira da Gama (2003, p.449) afirma que "o texto legal reconhece o recurso às técnicas de fertilização e de concepção para que haja a reprodução humana, o que conduz à constatação de que o direito brasileiro admite o recurso às técnicas conceptivas como inerentes aos direitos reprodutivos das pessoas". Neste mesmo contexto, ao editar o Código Civil de 2002, o Congresso Nacional estabeleceu no artigo $1565, \S 2^{\circ}$ do mencionado diploma legislativo que

o planejamento familiar é de livre decisão do casal, competindo ao Estado propiciar recursos educacionais e financeiros para o exercício desse direito, vedado qualquer tipo de coerção por parte de instituições privadas ou públicas.

Destacamos que, apesar de tal dispositivo estar elencado no capítulo que trata dos efeitos do casamento, este direito não está, de maneira alguma, adstrito às pessoas casadas. Afinal, a já referida Lei 9263/96 assegura o planejamento familiar ao casal, mas também à mulher e ao homem separadamente - em se tratando de norma específica, não foi revogada implicitamente pelo Código Civil, que tem natureza jurídica de lex generalis. Semelhantemente, por haver isonomia axiológica entre todas as diferentes formas de se constituir família, haveria inconstitucionalidade na imposição de limites infraconstitucionais ao planejamento familiar àquelas pessoas unidas pelo vínculo casamentário.

A ideia de planejamento familiar está intimamente relacionada com o "projeto parental", que podemos conceituar como a busca pela constituição de família, especificamente com a geração de descendentes. De acordo com Guilherme Calmon Nogueira da Gama (2003, p.715), “o projeto parental, no mundo contemporâneo, é essencial para as famílias, encontrando sua vocação mais autorizada e legítima na época do aumento da família com o nascimento de filhos". O mencionado autor segue afirmando que "a prole proporciona o desenvolvimento da família e sua continuidade". Ressaltamos que planejamento familiar e projeto parental não são expressões sinônimas. Neste sentido, Michelle Couto (2007, p.132) aduz que "a liberdade de fundar uma família pode, mas não de maneira necessária e obrigatória, acarretar na função procriativa", uma vez que há muitas entidades familiares na atualidade que não são constituídas 
por filhos. O projeto parental não é apenas um reflexo da pulsão natural inerente à função biológica de manutenção da espécie (COUTO, 2007, p.55). De fato, ele se articula com a ideologia dominante na sociedade, sendo influenciado pela religião, pela economia, entre outros (NASCIMENTO, 2009, p.07).

No contexto do planejamento famíliar e dos direitos reprodutivos e sexuais, temos a reprodução assistida. As técnicas de concepção assistida configuram uma verdadeira ruptura paradigmática na sociedade, na medida em que abrem espaço para redefinição de conceitos, a exemplo da inovadora ideia de "reprodução sem sexo". A biotecnologia "propiciou a dissociação das etapas reprodutivas do seu ciclo vital, de forma que o coito, a fecundação e a gestação tornaram-se possíveis em local e tempo diversos entre si” (FRAGA; AGUIAR, 2009, p.1.169). Com as alterações socioculturais, notadamente no que se refere à sexualidade, “os direitos reprodutivos passaram a ser encarados não no âmbito do fatalismo da procriação ou da esterilidade, mas como direitos das pessoas à realização pessoal e do casal no âmbito da sociedade" (GAMA, 2003, p.712). Caroline Sátiro de Holanda (2006, p.53) afirma que a tecnologia de procriação artificial ratifica "a livre escolha das pessoas ao planejamento familiar, sendo seu uso uma questão de liberdade e autonomia individual”. Dessa forma, podemos afirmar que, atualmente, as técnicas de reprodução assistida são exigidas, necessárias ou utilizadas em situações completamente distintas da infertilidade, como no caso do paciente aidético que quer ter filhos, mas não pode correr o risco numa relação sexual; ou o casal homossexual que não quer se relacionar com alguém do gênero oposto; ou o paciente que irá se submeter a determinado tratamento do qual surge a impotência como efeito colateral (CARNEIRO, 2005, p.39). Como manifestações do planejamento familiar, atualmente já vemos a reprodução assistida ser realizada após a morte do doador do material genético (reprodução assistida post mortem); ou com transferência de DNA mitocrondrial para garantir um mínimo vínculo genético entre a mãe registral e a criança concebida por doação de óvulos. Com base nas pesquisas científicas atualmente em estágio avançado, podemos antecipar os próximos passos, que um dia eram considerados impensáveis, de concretização do projeto parental: o desenvolvimento de úteros artificiais e a criação artificial de material genético (sêmen ou óvulos) a partir da derivação in vitro de células-tronco.

Com base em todo o exposto, depreendemos que a reprodução assistida post mortem é uma manifestação do direito constitucional ao planejamento familiar, possibilitada pelas tecnologias reprodutivas. Entretanto, para compreendermos a legitimidade de acesso à RAPM, 
devemos observar que essa técnica pode ser direcionada a concretizar o planejamento familiar: (a) da pessoa morta que deixou seus gametas criopreservados; (b) de uma pessoa viva que quer se utilizar especificamente desse material genético. É possível que os cenários (a) e (b) estejam relacionados em torno de um projeto parental comum, o que notadamente pode se verificar nas hipóteses de casamento ou união estável, mas isso não necessariamente ocorrerá.

Em primeiro lugar, o projeto parental e o planejamento familiar do(a) dono(a) dos gametas congelados independe do seu estado civil. Pessoas sozinhas, solteiras ou viúvas, são legitimadas a usar o seu material genético em vida, particularmente combinando-o com esperma ou óvulos doados e, em determinados casos, contando com o auxílio da gestação de substituição. Esses casos são as chamadas produções independentes, que são largamente aceitas tanto em relação a homens quanto a mulheres no direito brasileiro, sendo igualmente reconhecidas desde a proteção constitucional às famílias monoparentais até as normativas do CFM. Se isso é verdade enquanto o(a) dono(a) dos gametas congelados era vivo(a), continua sendo verdade mesmo após a sua morte. Se aceitamos a tutela póstuma do projeto parental de uma pessoa casada ou em união estável, não podemos negar essa tutela às pessoas sozinhas, sob pena de uma inconstitucional discriminação com base em estado civil. O teste dos melhores interesses da prole não pode ser utilizado em abstrato para barrar a RAPM na hipótese, na medida em que são constitucionalmente proibidas hierarquizações a priori de entidades familiares. Isso é particularmente verdadeiro nos casos em que claramente há uma ou mais pessoas que se responsabilizarão materialmente e afetivamente pela prole, como ilustrativamente os avós. Devemos sempre destacar: o que importa não é o estado civil da pessoa morta, e sim o seu consentimento para a RAPM. Obviamente, será necessário que alguém vivo se proponha a dar continuidade ao projeto parental estabelecido por aquele indivíduo. Ilustrativamente, vislumbramos a possibilidade em que, por testamento, o(a) dono(a) do material genético nomeia um herdeiro testamentário sob condição (ou encargo) de levar adiante a sua reprodução assistida post mortem e de se responsabilizar pelos filhos daí decorrentes. Esse seria um interessante caso para se discutir os efeitos sucessórios decorrentes da RAPM, incluindo a vocação hereditária da prole, a licitude do elemento acidental e até mesmo o possível rompimento do testamento.

Em segundo lugar, tanto a Constituição Federal quanto a lei 9263/1996 reconhecem o planejamento familiar como um direito com livre exercício. Obviamente não se está falando de um direito absoluto, na medida em que condicionado por outras normas do ordenamento 
jurídico, como a dignidade da pessoa humana, a parentalidade responsável e os melhores interesses da prole. Aqui falamos em livre exercício no sentido de que ninguém pode estabelecer coercitivamente como uma pessoa concretizará o seu planejamento familiar; a decisão cabe a ela, a ninguém mais. É constitucionalmente vedada a intervenção estatal ou privada nas decisões pertinentes ao planejamento familiar, seja essa intervenção positiva (determinar como o planejamento familiar será posto em prática) ou negativa (proibir formas como esse direito será exercido, ou pessoas com quem ele será concretizado). Em termos de reprodução assistida post mortem, entendemos que isso significa que não compete ao legislador, ao Conselho Federal de Medicina, à clínica de fertilização, ao eventual cônjuge ou companheiro(a) supérstite ou a qualquer ente público ou privado determinar quem pode e quem não pode ter acesso aos gametas criopreservados de uma pessoa morta. Essa decisão compete exclusivamente a quem está congelando o material genético, a ninguém mais.

Em terceiro lugar, é possível que o planejamento familiar da pessoa que quer ter acesso à RAPM para conceber filhos $d o(a)$ doador(a) morto(a) não signifique exatamente ter filhos com o(a) doador(a) morto(a). Conforme já mencionamos, planejamento familiar não se confunde com projeto parental. Observamos isso claramente no caso do pai ou da mãe de uma pessoa falecida que quer usar os gametas desta para conceber netos. Entendemos que se trata de uma forma de continuar a família, assegurar biologicamente a continuidade daquela família por pelo menos mais uma geração. Isso é particularmente verdadeiro se esses genitores já não estiverem mais em idade ou com interesse de ter outro(a) filho(a), por entender que o(a) morto(a) é insubstituível. Acreditamos que, para algumas pessoas, esse é um caminho para lidar com o luto, a dor e os sentimentos negativos decorrentes da perda de um(a) filho(a). Havendo a autorização do(a) doador(a) para isso, não há qualquer impedimento. Possivelmente também se fará necessária a combinação do material criopreservado com gametas doados por terceiro e a gestação por substituição. No caso específico ora comentado, visivelmente a pessoa que quer acessso à RAPM está concretizando o seu planejamento familiar por meio desse procedimento sem que isso necessariamente signifique que haverá vínculo de filiação com a prole. A ausência de vínculo específico de parentalidade obviamente não descarta a possibilidade de responsabilização material e afetiva pelas crianças concebidas postumamente, em atenção ao princípio dos melhores interesses. Com base nessa mesma hipótese ora discutida, percebemos a primeira evidência de que o acesso à RAPM independe de um vínculo de casamento ou união estável entre a pessoa que doou os gametas criopreservados e a pessoa que quer utilizar 
postumamente esse material genético.

Em quarto lugar, o supramencionado vínculo de casamento ou união estável não poderia ser exigido nem mesmo da pessoa que quer acesso à RAPM ter um filho com o(a) morto(a). Por um lado, abstratamente falando, o estado civil não é nem poderia ser elemento condicionante do acesso à reprodução assistida em sentido amplo; e essa premissa geral continua sendo válida para o caso específico de concepção póstuma. Por outro lado, em pleno 2020, parece-nos surreal que alguém ainda queria vincular o exercício do planejamento familiar ou do projeto parental a um vínculo (formal ou informal) entre os genitores. Esse vínculo de conjugalidade ou companheirismo não é critério determinante para o exercício dos direitos sexuais e reprodutivos pela via tradicional (coito). De modo muito mais evidente, tal vínculo jamais poderia condicionar o acesso à reprodução assistida, especialmente por se tratar de uma seara na qual o fator determinante é a manifestação de vontade informada e esclarecida no sentido de se submeter aos procedimentos. Por essa razão, acreditamos ser plenamente viável que alguém autorize o uso póstumo dos seus gametas por um(a) amigo(a) ou até mesmo pelo(a) concubino(a) ${ }^{6}$.

Conclusivamente, $\mathrm{o}$ acesso às tecnologias reprodutivas, inclusive a reprodução assistida post mortem, é um reflexo do direito constitucional ao planejamento familiar. O exercício deste direito é assegurado a todas as pessoas, independentemente do seu estado civil ou do vínculo que mantinham com o(a) falecido(a). De um lado, pessoas solteiras ou já viúvas (ou mesmo aquelas que vivem em arranjos familiares não tradicionalmente reconhecidos como tal - como os casos de poliamor) podem exercer seu planejamento familiar para autorizar o uso póstumo dos seus gametas. Por outro lado, pessoas vivas podem se utilizar de material genético criopreservado para conceber filhos $d o(a)$ morto(a), mas não com o(a) morto(a). Por fim, ainda que se trate de ter filhos com o(a) falecido(a), havendo a devida autorização, é desnecessário ter existido vínculo de casamento ou união estável entre a pessoa que doou o material genético e a pessoa que dele quer se utilizar postumamente.

\section{CONCLUSÃO}

6 Aqui nos referimos aos termos do artigo 1727 do Código Civil de 2002. Não há qualquer anacrônica confusão terminológica com a união estável. 
No presente artigo, depreendemos que o legislador brasileiro ainda não se preocupou em regulamentar adequadamente as técnicas de reprodução assistida, deixando dúvidas em relação a diversos aspectos das tecnologias reprodutivas. Observamos especificamente que inexiste lei em sentido estrito determinando quem é parte legítima para, por meio da reprodução assistida post mortem (RAPM), utilizar material criopreservado de pessoa já falecida.

Deduzimos que qualquer pessoa, independentemente do seu estado civil, pode optar tanto por congelar os seus gametas quanto por autorizar o uso póstumo destes. Do mesmo modo, inferimos que qualquer pessoa devidamente autorizada pelo(a) morto(a) poderá colocar em prática a RAPM, independentemente do seu estado civil. Da mesma forma, compreendemos que o acesso póstumo ao material germinativo se fundamenta no consentimento deixado pela pessoa que procedeu à criopreservação, e não a um eventual vínculo de casamento ou união estável entre esta e a pessoa que quer colocar a RAPM em prática.

Concluímos que o critério determinante para estabelecer a legitimidade de acesso à reprodução assistida post mortem é o consentimento da pessoa que criopreservou os gametas; o status familiar ou o vínculo entre os envolvidos são elementos irrelevantes para determinar quem pode colocar a RAPM em prática. Se não houve autorização, nem mesmo o cônjuge ou companheiro(a) supérstite poderá ter acesso póstumo ao material germinativo. Por outro lado, qualquer pessoa autorizada poderá proceder à RAPM, independentemente de ter mantido ou não um vínculo de casamento ou de união estável com o(a) doador(a) falecido(a).

\section{REFERÊNCIAS}

AGUIAR, Monica. Direito à filiação e bioética. Rio de Janeiro: Forense, 2005.

ALDROVANDI, Andrea. $\mathbf{O}$ acesso às tecnologias reprodutivas: garantias e limites jurídicos. 2006. Dissertação (Mestrado em Direito) - Faculdade de Direito, Universidade de Caxias do Sul, Caxias do Sul, 2006.

ALVES, Sandrina Maria Araújo Lopes; OLIVEIRA, Clara Costa. Reprodução medicamente assistida: questões bioéticas. In: Revista Bioética - v.22, n.1, 2014. Disponível em: $<$ http://revistabioetica.cfm.org.br/index.php/revista_bioetica/article/view/883/975>. Acesso em 2015-11-16. 
AUTO, Luciana da Fonseca Lima Brasileiro. Projeto individual de maternidade: entre o desejo e o direito. Dissertação (Mestrado em Direito) - Centro de Ciências Jurídicas da UFPE. Recife: Universidade Federal de Pernambuco, 2013.

BADALOTTI, Mariangela. Bioética e reprodução assistida. 2010. Disponível em: <http://www.pucrs.br/bioetica/cont/mariangela/bioeticaereproducao.pdf > . Acesso em 201511-16.

BELTRÃO, Silvio Romero. Reprodução humana assistida: conflitos éticos e legais: legislar é necessário. Tese (Doutorado em Direito) - Universidade Federal de Pernambuco. Recife: CCJ/UFPE, 2010.

BELTRÃO, Taciana Cahu. Uma análise civil-constitucional da monoparentalidade voluntária mediante o recurso da reprodução assistida. Dissertação (Mestrado em Direito) - Centro de Ciências Jurídicas da UFPE. Recife: Universidade Federal de Pernambuco, 2010.

BERALDO, Anna de Moraes Salles. Consequências jurídicas da reprodução humana assistida post mortem. In: Revista do Programa de Pós-Graduação em Direito da Universidade Federal da Bahia, n. 20. Salvador: Universidade Federal da Bahia, 2010.

DIAS, Maria Berenice. Manual de direito das famílias. $-4^{\mathrm{a}}$ ed. rev. atual. e ampl. São Paulo: Revista dos Tribunais, 2007.

DINIZ, Maria Helena. O estado atual do biodireito. São Paulo: Saraiva, 2007.

FARIAS, Cristiano Chaves de. Escritos de direito de família. Rio de Janeiro: Editora Lumen Juris, 2007.

FERNANDES, Silvia da Cunha. As técnicas de reprodução humana assistida e a necessidade de sua regulamentação jurídica. Rio de Janeiro: Renovar, 2005.

FERRAZ, Ana Claudia Brandão de Barros Correia. A reprodução humana assistida e suas consequências nas relações de família: a filiação e a origem genética sob a perspectiva da repersonalização. Dissertação (Mestrado em Direito) - Centro de Ciências Jurídicas da UFPE. Recife: Universidade Federal de Pernambuco, 2008.

GAMA, Guilherme Calmon Nogueira da. A nova filiação: o biodireito e as relações parentais. Rio de Janeiro: Renovar, 2003.

GUGLIOTTI, Kristine Barci. Reprodução artificial: limites necessários. Tese (Doutorado em Direito). Faculdade de Direito da Universidade de São Paulo. São Paulo: USP, 2014.

HIRONAKA, Giselda Maria Fernandes Novaes. A incessante travessia dos tempos e a renovação dos paradigmas: a família, seu status e seu enquadramento na pós- modernidade. Revista da Faculdade de Direito, Universidade de São Paulo, [S.1.], v. 101, p. 153-167, jan. 2006. ISSN 2318-8235. Disponível em:

<http://www.revistas.usp.br/rfdusp/article/view/67702>. Acesso em: 19 nov. 2015. 
. As inovações biotecnológicas e o direito das sucessões. Revista Jurídica: órgão nacional de doutrina, jurisprudência, legislação e crítica judiciária. Ano 57, no 375, janeiro de 2009. Porto Alegre: Notadez, 2009.

KRELL, Olga Jubert Gouveia. O direito fundamental à reprodução humana assistida no Brasil e suas repercussões na filiação civil: uma abordagem de lege ferenda. Tese (Doutorado em Direito) - Centro de Ciências Jurídicas da UFPE. Recife: Universidade Federal de Pernambuco, 2005.

LACERDA, Carmen Silvia Mauricio de. Monoparentalidade: um fenômeno em expansão. Dissertação (Mestrado) - Universidade Federal de Pernambuco. CCJ. Direito, 2006.

LAURA, Flavio. Da filiação no Novo Código Civil. In: Revista da EMERJ, número Especial: Anais do Seminário EMERJ Debate o Novo Código Civil, parte II, 2004. Disponível em:

<http://www.emerj.tjrj.jus.br/revistaemerj_online/edicoes/anais_onovocodigocivil/anais _especial_2/Anais_Parte_II_revistaemerj_84.pdf>. Acesso em 2015-11-17.

LEITE, Eduardo de Oliveira. Procriações artificiais e o direito: aspectos médicos, religiosos, psicológicos, éticos e jurídicos. São Paulo: Editora Revista dos Tribunais, 1995.

. Famílias monoparentais: a situação jurídica de pais e mães solteiros, de pais e mães separados e dos filhos na ruptura da vida conjugal. - 2. Ed., rev., atual. e ampl. São Paulo: Editora Revista dos Tribunais, 2003.

. Bioética e presunção de paternidade (considerações em torno do art. 1.597 do Código Civil). In: LEITE, Eduardo de Oliveira (Coord.) Grandes temas da atualidade: bioética e direito. Rio de Janeiro: Forense, 2004.

LÔBO, Paulo Luiz Netto. Princípios do direito de família brasileiro. In: Revista brasileira de direito comparado, n.35, jul/2008.

MAGALHÃES, Sandra Marques. Aspectos sucessórios da procriação medicamente assistida homóloga post mortem. Coimbra: Coimbra Editora, 2010.

MALUF, Adriana Caldas do Rego Freitas Dabus. Curso de bioética e biodireito. 2. ed. São Paulo: Atlas, 2013.

; MALUF, Carlos Alberto Dabus. A família na pós-modernidade: aspectos civis e bioéticos - R. Fac. Dir. Univ. São Paulo v. 108 p. 221 - 242 jan./dez. 2013.

MORI, Maurizio. Fecundação assistida e liberdade de procriação. In: Revista Bioética v.09, n.2, 2001.

ORSELLI, Helena de Azeredo. Questões controvertidas na filiação decorrente da reprodução assistida. Revista jurídica - vol.1, n.1/2 (jan/dez 1997). Blumenau: Universidade Regional de Blumenau, Centro de Ciências Jurídicas, 1997. 
PEREIRA, Rodrigo da Cunha. Princípios fundamentais norteadores do direito de família. - 2. Ed. - São Paulo: Saraiva, 2012.

PEREIRA JÚNIOR, Antonio Jorge. Hierarquia entre gêneros de convivência na Constituição Federal. Revista da Faculdade de Direito, Universidade de São Paulo, [S.1.], v. 98, p. 121134, jan. 2003. ISSN 2318-8235. Disponível em:

<http://www.revistas.usp.br/rfdusp/article/view/67582>. Acesso em: 19 nov. 2015.

PINHEIRO, Jorge Duarte. Procriação medicamente assistida. Texto disponibilizado em 2004. Disponível em:

<http://www.balzaca.info/biologia/downloads/Debate\%20aulas/procriacaomedicamente assistida.pdf $>$. Acesso em 2015-11-16.

SOUZA, Allan Rocha de; ALMEIDA JUNIOR, Vitor de Azevedo; CASTRO, Raul Murad Ribeiro de. Reprodução assistida, autonomia privada e personalidade: a questão dos embriões. Trabalho publicado nos Anais do XVII Encontro Preparatório para o Congresso Nacional do CONPEDI/UFBA - Salvador, realizado em Salvador - BA nos dias 19, 20 e 21 de junho de 2008. Disponível em:

<http://www.conpedi.org.br/manaus/arquivos/anais/salvado r/allan_rocha_de_souza.pdf $>$. Acesso em 2014-10-10.

SOUZA, Vanessa Ribeiro Corrêa Sampaio. O princípio da paternidade responsável: de suas diretrizes conceituais à influência sobre os efeitos decorrentes da filiação. Tese (Doutorado em Direito) - Universidade do Estado do Rio de Janeiro. Rio de Janeiro: Faculdade de Direito da UERJ, 2012.

SVITNEV, Konstantin. Legal regulation of assisted reproduction treatment in Russia. Reproductive BioMedicine Online, n. 20, 2010. Disponível em: https://www.rbmojournal.com/article/S1472-6483(10)00174-4/pdf. Acesso em 25 de setembro de 2020.

WIDER, Roberto. Reprodução assistida: aspectos do biodireto e da bioética. Rio de Janeiro: Editora Lumen Juris, 2007. 